\title{
The Alzheimer Variant of Lewy Body Disease: A Pathologically Confirmed Case-Control Study
}

\author{
R. Perneczky ${ }^{\mathrm{a}}$ D. Mösch ${ }^{\mathrm{a}}$ M. Neumann ${ }^{\mathrm{b}} \quad$ H. Kretzschmar ${ }^{\mathrm{b}} \quad$ U. Müller ${ }^{\mathrm{c}}$ \\ R. Busch ${ }^{d}$ H. Förstl ${ }^{a}$ A. Kurz ${ }^{a}$ \\ ${ }^{a}$ Klinik und Poliklinik für Psychiatrie und Psychotherapie der Technischen Universität München, \\ ${ }^{b}$ Institut für Neuropathologie der Ludwig-Maximilians-Universität München, München, ${ }^{\mathrm{C}}$ Institut für \\ Humangenetik der Justus-Liebig-Universität Giessen, Giessen, ${ }^{d}$ Institut für Medizinische Statistik und \\ Epidemiologie der Technischen Universität München, München, Deutschland
}

\section{Key Words}

Alzheimer-type dementia · Lewy body dementia •

Histopathology

\begin{abstract}
The objective of the study was to identify clinical features that distinguish patients with dementia with Lewy bodies (DLB), who were classified as Alzheimer's disease (AD) patients, from patients with $A D$. We examined a group of 27 patients from our memory clinic, originally diagnosed with $A D$, of whom 6 were postmortem found to have DLB. For the present study, we compared cognitive, noncognitive and neurological symptoms between the two groups. We found that there were no differences on ratings of dementia and scales for activities of daily living. Patients with DLB performed better on the MMSE and the memory subtest of the CAMCOG, but there was no difference in any other cognitive domain. Furthermore, genetic risk factors, including family history of dementia or allele frequency of the apolipoprotein $\varepsilon 4$, did not discriminate between the two groups, and there were no differences on CCT scans. Taken together, our findings suggest that Lewy body pathology may be present in patients who do not show the typical clinical features which distinguish DLB from AD.
\end{abstract}

Copyright $\Subset 2005$ S. Karger AG, Basel

\section{KARGER}

Fax +4161306 1234 E-Mail karger@karger.ch www.karger.com

\section{Introduction}

In 1990, the Lewy body variant of Alzheimer's disease (AD) [1], also termed senile dementia of Lewy body type [2] or dementia with Lewy bodies (DLB) [3], was described as a distinct neuropathological and clinical form of dementia in the elderly. Autopsy studies have shown that in $15-25 \%$ of elderly patients with dementia, Lewy bodies (LBs) are found in the cortex and brainstem in addition to various degrees of Alzheimer-type pathology. According to these studies, DLB may be the second most common cause of dementia after AD [1, 2, 4-6].

As noted in the initial descriptions of the condition, patients with DLB share many clinical features with typical AD including age, family history, history of onset, symptoms, duration of disease, mental status and degree of brain atrophy [7]. Symptoms that distinguish DLB from $\mathrm{AD}$ without Lewy body pathology are disproportional impairment of attention, executive function and visuospatial performance as well as mild extrapyramidal findings [1]. In studies on patients who met clinical and pathological criteria for $\mathrm{AD}$, however, no consistent association has been found between the presence of LBs and the frequency of these clinical features [3].

In addition to progressive dementia, the clinical consensus criteria [7] emphasize fluctuation of attention and alertness, recurrent visual hallucinations and spontane- 
ous motor features of Parkinsonism. Impairment of memory may be absent at early stages. Using these criteria, the sensitivity of the clinical diagnosis is $78 \%$, and the specificity is $64 \%$ as compared with neuropathological findings [8]. This is consistent with the finding that two thirds of patients with pathologically confirmed DLB have less than two core clinical features [8].

Here, we report on a small group of patients who fulfilled clinical criteria for AD [9] but were identified as having DLB at postmortem examination. The study was designed to determine whether classification of DLB as AD might have been avoided if distinguishing features had been observed, or whether there is a variant of DLB that cannot be separated from AD on clinical grounds.

\section{Methods}

\section{Patients}

From 1988 to 1992 , we conducted a prospective study which was designed to investigate the natural course and possible subtypes of $\mathrm{AD}$ [10]. A total of 90 patients were enrolled and re-examined at 12-month intervals for up to 3 years. All patients underwent a thorough diagnostic evaluation, which included psychiatric interview, physical examination, laboratory screening, cranial computed tomography and apolipoprotein E genotyping [11].

\section{Clinical Assessments and Diagnosis}

The clinical documentation included information on age, age at onset, years of education at school and family history of dementia. Impairment of cognitive function was assessed using the cognitive section (CAMCOG) of the Cambridge Mental Disorders of the Elderly Examination (CAMDEX) [12], which incorporates the MiniMental State Examination (MMSE). Out of 8 subscales of this standardized interview, 5 were considered in the present study (orientation, language, memory, praxis and perception). The CAMDEX protocol also provides information on activities of daily living (ADL) obtained from an informant (orientation in and around the home, performing household chores, handling money, eating, dressing, bladder and bowel control). For the present analysis, these variables were combined into an ADL score, higher values indicated greater impairment. Furthermore, informant ratings of noncognitive symptoms were taken from the CAMDEX standardized interview (hallucinations, paranoid ideation and fluctuating attention). These symptoms were rated as present or absent.

Neurological signs were documented in a standardized form. Of 10 signs recorded, gait disorder and increased muscle tone were selected and combined in a neurological score for the present analysis. Tremor was recorded as part of the CAMDEX documentation. Severity of dementia was rated on the Dementia Scale (DS) [13], the Global Deterioration Scale (GDS) [14] and the Clinical Dementia Rating (CDR) [15].

Based on this extensive information, a consensus diagnosis of $\mathrm{AD}$ was made by two experienced clinicians according to ICD-10 research criteria [9]. A probable $\mathrm{AD}$ was diagnosed using the
NINCDS-ADRDA criteria [16]. In 1996, Rasmussen et al. [17] showed that these diagnoses are $90 \%$ accurate. At the time of study, diagnostic criteria for DLB were not available, since they were only introduced in 1992 [18]. Patients who had marked neurological symptoms or a history of cerebrovascular accidents were not included.

\section{Neuropathological Evaluation and Diagnostic Criteria}

Brains were fixed in 4\% formalin in phosphate-buffered saline for at least 14 days. Representative blocks were embedded in paraffin and processed for routine histology. Sections $(4 \mu \mathrm{m})$ were cut and stained with hematoxylin and eosin, according to Gallyas and Bielschowsky silver impregnation. Immunohistochemistry was performed with anti-tau antibody AT8 (dilution 1:100; Innogenetics, Ghent, Belgium), anti-synuclein antibody 15G7 (dilution 1:10), anti- $\beta$ amyloid peptide antibody (1:100; Dako, Glostrup, Denmark) and anti-ubiquitin antiserum (1:300; Dako). Antibody binding was detected using the Dako alkaline phosphatase/anti-alkaline phosphatase system and neufuchsin as chromogen.

The pathological diagnosis was made using established international criteria. Alzheimer's pathology was classified using the CERAD pathologic criteria, based on semiquantitative analysis of neuritic plaques [19], as well as the Braak and Braak classification, based on the distribution of neurofibrillary tangles and neuropil threads [20].

Distribution and frequency of LBs were evaluated according to consensus guidelines for diagnosing DLB [7]. The number of LBs was counted in the therein defined brain regions using $\alpha$-synuclein immunohistochemistry and was converted into scores of 0 (no LBs), 1 (1-4 LBs) and 2 (>5 LBs) for each area. Based on the total score, cases were divided into 3 subtypes: brainstem predominant, limbic and neocortical.

The neuropathological diagnosis of DLB was made if LBs were present in the diagnostic areas, irrespective of the severity of AD pathology.

The diagnosis of dementia lacking distinctive histopathology (DLDH) and corticobasal degeneration (CBD) was made according to McKhann et al. [21] and Dickson et al. [22], respectively.

Postmortem diagnosis was attempted in as many patients as possible. Of the 66 patients who had died between 1988 and 1997 , autopsy was obtained in 27 cases. The clinical diagnosis of AD was confirmed in 19 patients, 6 patients had additional Lewy body pathology and were classified as DLB. Two patients showed no ADrelated pathology and were diagnosed as DLDH or CBD. Neuropathological information is shown in table 1 .

\section{Apolipoprotein E Genotyping}

The apolipoprotein E genotype was determined according to the procedures described previously [23].

\section{Data Analysis}

Statistical analysis was performed using the Statistical Package for the Social Sciences [24], version 10.0. Demographic data, severity ratings (MMSE, DS, GDS, CDR), CAMCOG subscores, ADL, $\mathrm{BEH}$ and neurological scores were compared between AD and DLB patients applying $\chi^{2}$ tests for frequencies and linear regression analysis for group means, controlling for age at onset and education. 
Table 1. Neuropathological information

\begin{tabular}{|c|c|c|c|c|c|c|}
\hline Case & Sex & Age & $\begin{array}{l}\text { Diag- } \\
\text { nosis }\end{array}$ & CERAD & $\begin{array}{l}\text { Braak and } \\
\text { Braak stage }\end{array}$ & $\begin{array}{l}\text { LB pathol- } \\
\text { ogy }\end{array}$ \\
\hline 1 & $\mathrm{~F}$ & 72 & $\mathrm{AD}$ & $\mathrm{C}$ & VI & none \\
\hline 2 & M & 74 & $\mathrm{AD}$ & $\mathrm{C}$ & $\mathrm{V}$ & none \\
\hline 3 & $\mathrm{~F}$ & 68 & $\mathrm{AD}$ & $\mathrm{C}$ & VI & none \\
\hline 4 & $\mathrm{~F}$ & 73 & $\mathrm{AD}$ & $\mathrm{C}$ & VI & none \\
\hline 5 & $\mathrm{~F}$ & 78 & $\mathrm{AD}$ & $\mathrm{C}$ & VI & none \\
\hline 6 & M & 83 & $\mathrm{AD}$ & $\mathrm{C}$ & VI & none \\
\hline 7 & M & 80 & $\mathrm{AD}$ & $\mathrm{C}$ & VI & none \\
\hline 8 & $\mathrm{~F}$ & 70 & $\mathrm{AD}$ & $\mathrm{C}$ & $\mathrm{V}$ & none \\
\hline 9 & M & 63 & $\mathrm{AD}$ & $\mathrm{C}$ & $\mathrm{V}$ & none \\
\hline 10 & $\mathrm{~F}$ & 70 & $\mathrm{AD}$ & $\mathrm{C}$ & $\mathrm{V}$ & none \\
\hline 11 & $\mathrm{~F}$ & 71 & $\mathrm{AD}$ & $\mathrm{C}$ & VI & none \\
\hline 12 & $\mathrm{~F}$ & 72 & $\mathrm{AD}$ & $\mathrm{C}$ & VI & none \\
\hline 13 & $\mathrm{~F}$ & 89 & $\mathrm{AD}$ & $\mathrm{C}$ & IV & none \\
\hline 14 & M & 81 & $\mathrm{AD}$ & $\mathrm{C}$ & $\mathrm{V}$ & none \\
\hline 15 & $\mathrm{~F}$ & 83 & $\mathrm{AD}$ & $\mathrm{C}$ & V & none \\
\hline 16 & $\mathrm{~F}$ & 81 & $\mathrm{AD}$ & $\mathrm{C}$ & V & none \\
\hline 17 & $\mathrm{~F}$ & 84 & $\mathrm{AD}$ & $\mathrm{C}$ & $\mathrm{V}$ & none \\
\hline 18 & $\mathrm{~F}$ & 63 & $\mathrm{AD}$ & $\mathrm{C}$ & VI & none \\
\hline 19 & $\mathrm{~F}$ & 70 & $\mathrm{AD}$ & $\mathrm{C}$ & VI & none \\
\hline 20 & $\mathrm{~F}$ & 79 & DLB & $\mathrm{C}$ & $\mathrm{V}$ & neocortical \\
\hline 21 & $\mathrm{~F}$ & 85 & DLB & $\mathrm{C}$ & V-VI & neocortical \\
\hline 22 & $\mathrm{~F}$ & 80 & DLB & $\mathrm{C}$ & V-VI & neocortical \\
\hline 23 & $\mathrm{~F}$ & 79 & DLB & $\mathrm{C}$ & $\mathrm{V}$ & neocortical \\
\hline 24 & $\mathrm{~F}$ & 85 & DLB & $\mathrm{C}$ & $\mathrm{V}$ & neocortical \\
\hline 25 & $\mathrm{~F}$ & 80 & DLB & $\mathrm{C}$ & V-VI & neocortical \\
\hline 26 & $\mathrm{~F}$ & 78 & DLDH & 0 & I & none \\
\hline 27 & M & 69 & CBD & B & II & none \\
\hline
\end{tabular}

\section{Results}

\section{Demographic Data}

Patients with AD and DLB did not differ significantly regarding gender distribution and years of education. However, DLB patients were significantly older than AD patients (table 2). A family history of dementia was found in $26 \%$ in $\mathrm{AD}$ and $33 \%$ in DLB cases (table 3 ).

\section{Apolipoprotein E Genotype}

Of the 19 patients with $\mathrm{AD}, 14$ were carriers of the apolipoprotein E $\varepsilon 4$ allele, whereas only 3 of 6 patients with DLB were $\varepsilon 4$ positive. The $\varepsilon 4$ allele frequency was 0.42 in the AD group and 0.50 in the DLB group. This difference was not statistically significant $(p=0.12)$ (table 3).

\section{Cranial Computed Tomography}

Brain atrophy was seen in 13 out of 17 patients with $\mathrm{AD}(76 \%)$ for whom $\mathrm{CT}$ scans were available and in 5
Table 2. Demographic data

\begin{tabular}{lccc}
\hline Variable & AD $(\mathrm{n}=19)$ & DLB $(\mathrm{n}=6)$ & $\mathrm{p}$ value \\
\hline Females:males & $15: 4$ & $5: 1$ & 0.82 \\
Family history, yes:no & $5: 14$ & $2: 4$ & 0.74 \\
Education, years & $9.5 \pm 1.7$ & $9.0 \pm 1.8$ & 0.51 \\
Age at onset, years & $66.2 \pm 7.9$ & $74.4 \pm 3.7$ & 0.03 \\
\hline
\end{tabular}
$\mathrm{SD}$.

Figures for education and age at onset are expressed as mean \pm

Table 3. Genetic variables and cranial computed tomography (CCT) findings

\begin{tabular}{lccc}
\hline Variable & AD & DLB & p value \\
\hline ApoE $\varepsilon 4$ allele frequency & 0.42 & 0.50 & 0.12 \\
Brain atrophy on CCT & 0.77 & 0.83 & 0.73 \\
Family history of dementia & 0.26 & 0.33 & 0.74 \\
\hline
\end{tabular}

patients with DLB (83\%). This difference did not reach statistical significance (table 3 ).

\section{Severity of Dementia}

Although they were significantly older, patients with DLB achieved a higher cognitive performance on the MMSE than patients with AD (table 4). Due to the small sample size, the difference of 4 points on the scale was not of statistical significance. General severity of dementia, as assessed using the DS, GDS or CDR, was not different between the two diagnostic groups.

\section{Cognitive Ability}

There was no statistically significant difference on any CAMCOG subscale between the two diagnostic groups (table 4). Fluctuation of attention was not observed in either group.

\section{Noncognitive Symptoms}

Hallucinations were present in 2 out of 6 patients with DLB and in 1 out of 19 patients with AD. This difference fell short of reaching statistical significance (table 4).

\section{ADL and Neurological Symptoms}

There were no statistically significant differences between the diagnostic groups with regard to these symptoms (table 5). Furthermore, tremor was absent in both groups. 
Table 4. Psychopathological symptoms

\begin{tabular}{lccl}
\hline Variable & AD $(\mathrm{n}=19)$ & DLB $(\mathrm{n}=6)$ & $\mathrm{p}$ value \\
\hline MMSE & $14.9 \pm 4.9$ & $18.8 \pm 3.2$ & 0.06 \\
$\mathrm{DS}$ & $12.2 \pm 4.8$ & $14.7 \pm 4.3$ & 0.09 \\
GDS, 4/5/6 & $3 / 13 / 3$ & $1 / 4 / 1$ & 1.00 \\
CDR, 1/2/3 & $8 / 10 / 1$ & $3 / 3 / 0$ & 0.82 \\
Orientation & $3.1 \pm 1.9$ & $5.0 \pm 3.4$ & 0.94 \\
Language & $17.5 \pm 5.7$ & $18.7 \pm 7.4$ & 0.82 \\
Memory & $3.6 \pm 3.3$ & $7.5 \pm 3.7$ & 0.10 \\
Praxis & $6.7 \pm 2.6$ & $6.2 \pm 3.1$ & 0.67 \\
Perception & $4.6 \pm 3.2$ & $4.3 \pm 2.1$ & 0.89 \\
Delusions, no/yes & $17 / 2$ & $4 / 2$ & 0.23 \\
Hallucinations, no/yes & $19 / 1$ & $4 / 2$ & 0.13 \\
ADL & $7.0 \pm 4.4$ & $8.0 \pm 4.2$ & 0.66 \\
\hline
\end{tabular}

Figures are expressed as mean $\pm \mathrm{SD}$, except for GDS, CDR, delusions and hallucinations.

\section{Discussion}

The present study refers to a highly selected group of patients who were referred to a university memory clinic for diagnostic evaluation. All patients included in this study fulfilled ICD-10 research criteria for AD [9]. At postmortem examination, AD was confirmed in 19 of these patients, but 6 subjects were found to have DLB. All cases classified as DLB had severe Alzheimer-related pathology (CERAD C and Braak and Braak stage V-VI) in addition to significant Lewy body counts in diagnostically important areas. In the present paper, we compare cognitive, noncognitive and neurological symptoms between the two groups at the time of enrollment. The objective of the study was to identify clinical features that distinguish patients with DLB who were classified as AD from patients with $A D$.

Patients with DLB were significantly older at onset of symptoms than $\mathrm{AD}$ patients. On ratings of dementia severity, the two groups were identical, the majority of patients showing a moderate degree of intellectual impairment. Furthermore, there was no difference in the ability to carry out ADL. On the MMSE, however, patients with DLB had higher average scores than patients with AD, suggesting that their cognitive performance was better. This is consistent with a nonsignificantly higher score on the memory subtest of the CAMCOG. There was no difference between the groups in any other cognitive domain. This indicates that the profile of cognitive abilities may not be useful for the differentiation between $\mathrm{AD}$ and DLB.
Table 5. ADL and neurological symptoms

\begin{tabular}{lccc}
\hline Variable & $\begin{array}{l}\mathrm{AD} \\
(\mathrm{n}=19)\end{array}$ & $\begin{array}{l}\mathrm{DLB} \\
(\mathrm{n}=6)\end{array}$ & $\mathrm{p}$ value \\
\hline ADL & $\begin{array}{c}7.0 \pm 4.4 \\
17 / 2\end{array}$ & $\begin{array}{c}8.0 \pm 4.2 \\
6 / 0\end{array}$ & $\begin{array}{c}0.66 \\
0.41\end{array}$ \\
\hline
\end{tabular}

Figures for ADL are expressed as mean $\pm \mathrm{SD}$.

Even though present clinical diagnostic criteria for DLB were not available at the time of our study, we feel confident that the clinical assessment covered all the important early signs of DLB. Typical symptoms, such as fluctuating attention, visual hallucinations and tremor, are part of the CAMDEX interview, and neurological symptoms with focus on additional features of Parkinsonism were recorded in a standardized form. Parkinsonian symptoms, in particular tremor, gait disorder and increased muscle tone, were absent in both groups. Another major feature of DLB [7] was absent in the DLB group, namely fluctuating attention. Furthermore, hallucinations were only present in one third of these individuals. There have been previous comparisons between AD and DLB in patients with neuropathologically confirmed diagnosis, which also did not find any differences regarding cognitive impairment, hallucinations and fluctuating attention [25]. A recent study comes to the similar conclusion that patients with significant tangle pathology who are pathologically assigned a DLB diagnosis were clinically indistinguishable from $\mathrm{AD}$ [26]. On the other hand, there are authors who report that visual hallucinations are more common in DLB [27, 28] and suggest that the distinction between AD and DLB may be improved by greater emphasis on hallucinations [29]. Furthermore, some studies found a significantly higher impairment of attention in patients with DLB [30] and more fluctuations of attention compared with patients who suffered from $\operatorname{AD}[31,32]$. Fluctuating attention also has a significant impact on ADL [33].

Genetic risk factors also did not discriminate between the groups; approximately one third of the DLB and AD patients had a positive family history of dementia, and the apolipoprotein E $\varepsilon 4$ allele frequency was elevated above control values to a similar extent in both groups. This finding is consistent with several other studies which also found no difference in the $\varepsilon 4$ allele frequency between AD and DLB [34-36]. In addition, the frequency of atrophic changes seen on CT scans was not different 
between the two groups. Previous studies have found a strong correlation between DLB and occipital deficits in cerebral perfusion [37] and glucose metabolism [38, 39]. However, as was the case in the present study, no changes in occipital brain structure were seen [40] and the CT or MRI findings did not differ between the two types of dementia [41].

Taken together, our findings suggest that Lewy body pathology may be present in patients who do not show any of the clinical features which distinguish DLB from $\mathrm{AD}$ according to present diagnostic criteria. This is consistent with the sensitivity of these criteria of $78 \%$, which has been found in clinicopathological correlations [8]. Di- agnostic sensitivity may possibly be improved by including more sensitive tests of attention and executive ability in the neuropsychological evaluation and by using the full range of diagnostic possibilities, such as positron emission tomography [39, 42, 43], brain perfusion scintigraphy [44] and liquor markers [45-47].

\section{Acknowledgement}

This study was supported in part by the Federal Ministry of Research and Technology, grant No. 701770/3 and the Federal Ministry of Education and Research, grant No. 01/GI9999/1.

We thank Iryna Pigur for excellent experimental assistance.

\section{References}

1 Hansen L, Salmon D, Galasko D, Masliah E, Katzman R, DeTeresa R, Thal L, Pay MM, Hofstetter R, Klauber M: The Lewy body variant of Alzheimer's disease: A clinical and pathologic entity. Neurology 1990;40:1-8.

2 Perry RH, Irving D, Blessed G, Fairbairn A, Perry EK: Senile dementia of Lewy body type. A clinically and neuropathologically distinct form of Lewy body dementia in the elderly. $\mathrm{J}$ Neurol Sci 1990;95:119-139.

3 Stern Y, Jacobs D, Goldman J, Gomez-Tortosa E, Hyman B T, Liu Y, Troncoso J, Marder K, Tang MX, Brandt J, Albert M: An investigation of clinical correlates of Lewy bodies in autopsy-proven Alzheimer disease. Arch Neurol 2001;58:460-465.

4 Kosaka K, Yoshimura M, Ikeda K, Budka H: Diffuse type of Lewy body disease: Progressive dementia with abundant cortical Lewy bodies and senile changes of varying degree - a new disease? Clin Neuropathol 1984;3:185-192.

5 Lennox G, Lowe J, Morrell K, Landon M, Mayer RJ: Anti-ubiquitin immunocytochemistry is more sensitive than conventional techniques in the detection of diffuse Lewy body disease. J Neurol Neurosurg Psychiatry 1989;52:67-71.

6 Dickson DW, Ruan D, Crystal H, Mark MH, Davies P, Kress Y, Yen SH: Hippocampal degeneration differentiates diffuse Lewy body disease (DLBD) from Alzheimer's disease: Light and electron microscopic immunocytochemistry of CA2-3 neurites specific to DLBD. Neurology 1991;41:1402-1409.

7 McKeith IG, Galasko D, Kosaka K, Perry EK, Dickson DW, Hansen LA, Salmon DP, Lowe J, Mirra SS, Byrne EJ, Lennox G, Quinn NP, Edwardson JA, Ince PG, Bergeron C, Burns A, Miller BL, Lovestone S, Collerton D, Jansen ENH, Ballard C, de-Vos RAI, Wilcock GK, Jellinger KA, Perry RH: Consensus guidelines for the clinical and pathologic diagnosis of dementia with Lewy bodies (DLB): Report of the consortium on DLB international workshop. Neurology 1996;47:1113-1124.
8 Verghese J, Crystal HA, Dickson D W, Lipton RB: Validity of clinical criteria for the diagnosis of dementia with Lewy bodies. Neurology 1999;53:1974-1982.

9 Dilling H, Mombour W, Schmidt M H, Schulte-Markwort E (eds): Weltgesundheitsorganisation: Internationale Klassifikation psychischer Störungen. ICD-10 Kapitel V(F) Forschungskriterien. Bern, Huber, 1994.

10 Kurz A, Haupt M, Pollmann S, Romero B: Alzheimer's disease: Is there evidence of phenomenological subtypes? Dementia 1992;3: 320-327.

11 Kurz A, Lautenschlager N, Haupt M, Zimmer R, Von-Thülen B, Altlandt K, Lauter H, Müller U: Das Apolipoprotein-E-e4-Allel ist ein Risikofaktor für die Alzheimer-Krankheit mit frühem und spätem Beginn. Nervenarzt 1994; 65:774-779.

12 Roth M, Tym E, Mountjoy CQ, Huppert FA, Hendrie H, Verma S, Goddard R: CAMDEX. A standardized instrument for the diagnosis of mental disorder in the elderly with special reference to the early detection of dementia. Br J Psychiatry 1986;149:698-709.

13 Blessed G, Tomlinson BE, Roth M: The association between quantitative measures of dementia and the senile change in the cerebral grey matter of elderly subjects. Br J Psychiatry 1968;114:797-811.

14 Reisberg B, Ferris SH, de-Leon M, Crook T: The Global Deterioration Scale for assessment of primary degenerative dementia. Am J Psychiatry 1982;139:1136-1139.

15 Hughes CP, Berg L, Danziger WL, Coben LA, Martin RL: A new clinical scale for the staging of dementia. Br J Psychiatry 1982;140:566572.

16 McKhann G, Folstein M, Katzman R, Price D, Stadlan EM: Clinical diagnosis of Alzheimer's disease: Report of the NINCDS-ADRDA work group under the auspices of Department of Health and Human Services Task Force on Alzheimer's Disease. Neurology 1984;34:939-944.
17 Rasmussen DX, Brandt J, Steele C, Hedreen JC, Troncoso JC, Folstein MF: Accuracy of clinical diagnosis of Alzheimer disease and clinical features of patients with non-Alzheimer disease neuropathology. Alzheimer Dis Assoc Disord 1996;10:180-188.

18 McKeith IG, Perry RH, Fairbairn A: Operational criteria for senile dementia of Lewy body type (SDLT). Psychol Med 1992;22:911-922.

19 Mirra SS, Heyman A, McKeel D, Sumi SM, Crain BJ, Brownlee LM, Vogel FS, Hughes JP, van Belle G, Berg L: The Consortium to Establish a Registry for Alzheimer's Disease (CERAD). II. Standardization of the neuropathologic assessment of Alzheimer's disease. Neurology 1991;41:479-486.

20 Braak H, Braak E: Neuropathological staging of Alzheimer-related changes. Acta Neuropathol (Berl) 1991;82:239-259.

21 McKhann GM, Albert MS, Grossman M, Miller B, Dickson D, Trojanowski JQ: Clinical and pathological diagnosis of frontotemporal dementia: Report of the Work Group on Frontotemporal Dementia and Pick's Disease. Arch Neurol 2001;58:1803-1809.

22 Dickson DW, Bergeron C, Chin SS, Duyckaerts C, Horoupian D, Ikeda K, Jellinger K, Lantos PL, Lippa CF, Mirra SS, Tabaton M, Vonsattel JP, Wakabayashi K, Litvan I: Office of Rare Diseases neuropathologic criteria for corticobasal degeneration. J Neuropathol Exp Neurol 2002;61:935-946.

23 Kurz A, Egensperger R, Haupt M, Lautenschlager N, Romero B, Graeber MB, Müller U: Apolipoprotein $\mathrm{E}$ allele $\varepsilon 4$, cognitive decline, and deterioration of everyday performance in Alzheimer's disease. Neurology 1996;47:440_ 443.

24 Norusis MJ: SPSS Statistical Package for the Social Sciences. Chicago, SPSS, 1994

25 Förstl H, Burns A, Luthert P, Cairns N, Levy R: The Lewy-Body variant of Alzheimer's disease. Br J Psychiatry 1993;162:385-392. 
26 Ballard CG, Jacoby R, Del Ser T, Khan MN, Munoz DG, Holmes C, Nagy Z, Perry EK, Joachim C, Jaros E, O'Brien JT, Perry RH, McKeith IG: Neuropathological substrates of psychiatric symptoms in prospectively studied patients with autopsy-confirmed dementia with Lewy bodies. Am J Psychiatry 2004;161: 843-849.

27 Ballard C, McKeith I, Harrison R, O'Brien J, Thompson P, Lowery K, Perry R, Ince P: A detailed phenomenological comparison of complex visual hallucinations in dementia with Lewy bodies and Alzheimer's disease. Int Psychogeriatr 1997;9:381-388.

28 Rockwell E, Choure J, Galasko D, Olichney J, Jeste DV: Psychopathology at initial diagnosis in dementia with Lewy bodies versus Alzheimer disease: Comparison of matched groups with autopsy-confirmed diagnoses. Int J Geriatr Psychiatry 2000;15:819-823.

29 Hohl U, Tiraboschi P, Hansen LA, Thal LJ, Corey-Bloom J: Diagnostic accuracy of dementia with Lewy bodies. Arch Neurol 2000;57: 347-351.

30 Calderon J, Perry RJ, Erzinclioglu SW, Berrios GE, Dening TR, Hodges JR: Perception, attention, and working memory are disproportionately impaired in dementia with Lewy bodies compared with Alzheimer's disease. J Neurol Neurosurg Psychiatry 2001;70:157-164.

31 Walker MP, Ayre GA, Perry EK, Wesnes K, McKeith IG, Tovee M, Edwardson JA, Ballard CG: Quantification and characterization of fluctuating cognition in dementia with Lewy bodies and Alzheimer's disease. Dement Geriatr Cogn Disord 2000;11:327-335.

32 Ballard C, O’Brien J, Gray A, Cormack F, Ayre G, Rowan E, Thompson P, Bucks R, McKeith I, Walker M, Tovee M: Attention and fluctuating attention in patients with dementia with Lewy bodies and Alzheimer disease. Arch Neurol 2001;58:977-982.
33 Ballard C, Walker M, O’Brien J, Rowan E, McKeith I: The characterisation and impact of 'fluctuating' cognition in dementia with Lewy bodies and Alzheimer's disease. Int J Geriatr Psychiatry 2001;16:494-498.

34 Galasko D, Saitoh T, Xia Y, Thal LJ, Katzman R, Hill LR, Hansen L: The apolipoprotein E allele $\varepsilon 4$ is overrepresented in patients with the Lewy body variant of Alzheimer's disease. Neurology 1994;44:1950-1951.

35 Lippa CF, Smith TW, Saunders AM, Crook R, Pulaski-Salo D, Davies P, Hardy J, Roses AD, Dickson D: Apolipoprotein E genotype and Lewy body disease. Neurology 1995;45:97103.

36 Singleton $\mathrm{AB}$, Wharton A, O'Brien KK, Walker MP, McKeith I G, Ballard CG, O'Brien J, Perry RH, Ince PG, Edwardson JA, Morris $\mathrm{CM}$ : Clinical and neuropathological correlates of apolipoprotein E genotype in dementia with Lewy bodies. Dement Geriatr Cogn Disord 2002;14:167-175.

37 Lobotesis K, Fenwick JD, Phipps A, Ryman A, Swann A, Ballard C, McKeith IG, O'Brien JT: Occipital hypoperfusion on SPECT in dementia with Lewy bodies but not AD. Neurology 2001;56:643-649.

38 Minoshima S, Foster NL, Sima AA, Frey KA, Albin RL, Kuhl DE: Alzheimer's disease versus dementia with Lewy bodies: Cerebral metabolic distinction with autopsy confirmation. Ann Neurol 2001;50:358-365.

39 Higuchi M, Tashiro M, Arai H, Okamura N, Hara S, Higuchi S, Itoh M, Shin RW, Trojanowski JQ, Sasaki H: Glucose hypometabolism and neuropathological correlates in brains of dementia with Lewy bodies. Exp Neurol 2000;162:247-256.

40 Middelkoop HA, van der Flier WM, Burton EJ, Lloyd AJ, Paling S, Barber R, Ballard C, McKeith IG, O'Brien JT: Dementia with Lewy bodies and $\mathrm{AD}$ are not associated with occipital lobe atrophy on MRI. Neurology 2001;57: 2117-2120.
41 O'Brien JT, Paling S, Barber R, Williams ED, Ballard C, McKeith IG, Gholkar A, Crum WR, Rossor MN, Fox NC: Progressive brain atrophy on serial MRI in dementia with Lewy bodies, $\mathrm{AD}$, and vascular dementia. Neurology 2001;56:1386-1388.

42 Mirzaei S, Knoll P, Koehn H, Bruecke T: Assessment of diffuse Lewy body disease by 2 (18F)fluoro-2-deoxy- $D$-glucose positron emission tomography (FDG PET). BMC Nucl Med 2003;3:1

43 Okamura N, Arai H, Higuchi M, Tashiro M, Matsui T, Hu XS, Takeda A, Itoh M, Sasaki H: $\left({ }^{18} \mathrm{~F}\right)$ FDG-PET study in dementia with Lewy bodies and Alzheimer's disease. Prog Neuropsychopharmacol Biol Psychiatry 2001;25: 447-456.

44 Donnemiller E, Heilmann J, Wenning GK, Berger W, Decristoforo C, Moncayo R, Poewe W, Ransmayr G: Brain perfusion scintigraphy with $99 \mathrm{mTc}$-HMPAO or $99 \mathrm{mTc}-\mathrm{ECD}$ and 123I-beta-CIT single-photon emission tomography in dementia of the Alzheimer-type and diffuse Lewy body disease. Eur J Nucl Med 1997;24:320-325.

45 Kanemaru K, Kameda N, Yamanouchi H: Decreased CSF amyloid beta42 and normal tau levels in dementia with Lewy bodies. Neurology 2000;54:1875-1876.

46 Tschampa HJ, Schulz-Schaeffer W, Wiltfang J, Poser S, Otto M, Neumann M, Kretzschmar HA: Decreased CSF amyloid beta42 and normal tau levels in dementia with Lewy bodies. Neurology 2001;56:576.

47 Parnetti L, Lanari A, Amici S, Gallai V, Vanmechelen E, Hulstaert F, Phospho-Tau International Study G: CSF phosphorylated tau is a possible marker for discriminating Alzheimer's disease from dementia with Lewy bodies. Phospho-Tau International Study Group. Neurol Sci 2001;22:77-78. 